\title{
Gear mesh geometry effect on performance improvement for external gear pumps
}

\author{
Viktor Ivanov ${ }^{1, *}$, Dimitar Karaivanov ${ }^{2}$, Svitlana Ivanova $^{3}$, and Mariia Volkova ${ }^{3}$ \\ ${ }^{1}$ Odessa National Polytechnic University, Ukraine \\ ${ }^{2}$ University of Chemical Technology and Metallurgy - Sofia, Bulgaria \\ ${ }^{3}$ South Ukrainian National Pedagogical University named after K. D. Ushynsky, Ukraine
}

\begin{abstract}
The parameters of the involute and cycloidal gearing which influence on fluid volume at the tooth space are analysed. It is established that to a greater extent on the flow rate of the pump with involute gearing is influenced by the radial clearance coefficient and the profile shift coefficient. The radii ratio of the auxiliary and pitch circles, as well as the radial clearance coefficient, mainly affect the flow rate of the pump with cycloidal gearing. Since the gear module is determined for reasons of pump flow rate, the teeth has a significant safety factor for contact stress and especially bending stress. This allows a wide variation of the gearing parameters in greater limits than in transmissions. The dependences of the fluid volume at the tooth space in the cycloidal gearing on the radial clearance coefficient, on the radii ratio of the auxiliary and pitch circles, on the fillet radius coefficient, is found. The boundaries of the variation of the gearing parameters were established taking into account the bending strength of the teeth. The analysis is carried out using the finite element method. Recommendations for the use of cycloidal gearing in external gear pumps have been developed.
\end{abstract}

\section{Introduction}

Invented more than a century ago, gear pumps are today the most preferred type of pump for working with viscous fluids (petroleum products, oils, chocolate, etc.). They can be successfully used as an alternative of centrifugal pumps in cases where a "careful" transfer of fluid is required. The pump parameters are almost completely determined by the gear train parameters. Analysis of the known methods of increasing the gear pump flow rate showed that today almost all known methods should be classified as extensive. Increased flow rate is provided by a proportional increase in the geometric dimensions of the gears and the pump. This transmission is almost always underloaded, because its module is chosen not on the basis of strength calculation, but on the basis of the calculation of the pump performance. In the case when the pump is used to lubricate viscous fluids, rotation takes place at a low speed and the issue of flow fluctuations is not so important. This makes it possible to use gear pumps with parameters that are not commonly used. Known studies, where non-standard and even not recommended geometric parameters are used for increase the volume of fluid located in the tooth space.

Advances in the gear manufacturing technology have led to decrease in the amount of gears, manufactured through cutting. Modern machinery utilizes gears manufactured through casting, stamping and sintering [1, 2]. Thus, one may avoid the otherwise obligatory link between the tooth profile and the parameters of the cutting tool - rack cutter, gear-shaper cutter and gear hobbing cutter. The use of milling machines with $\mathrm{CNC}$ (computer numerical control) enables the manufacturing of a random tooth profile. Therefore, the technological limitations that have led to the general use of the involute tooth system vanish [3]. In this regard, the topic of using epicycloids and hypocycloids for tooth profiling is brought forth. The use of cycloidal gearing gear pumps external gearing provides an increase in their performance at a sufficient structural strength.

\section{Literature review and problem statement}

A mathematical model of a gear pump with involute gearing was created in the study [4]. The dependence of a pump flow rate on the complex of geometric parameters of involute gearing is established. Increasing the addendum diameter of the gear increases flow rate but not significantly. An increase the addendum diameter is introduced due to an increase in the tooth addendum coefficient $h_{a}{ }^{*}$. The possibilities for increasing the addendum diameter of the gears of the pumping unit are very limited.

Increasing the number of gear teeth reduces flow rate. An increase of the teeth number with the same dimensions of the pump cavity is possible with a simultaneous reduction of the gear module. Therefore, the above statements can be interpreted as increasing flow rate by increasing the gear module at constant pump unit dimensions [4]. 
Reduced flow rate occurs when increasing the pressure angle $\alpha_{\omega}$. The use of gears with the pressure angle of $15^{\circ} \ldots 18^{\circ}$ degrees is recommended. Increasing the addendum coefficient $\mathrm{h}_{\mathrm{a}}{ }^{*}$ from 1.0 to 1.25 increases the pump flow rate. This conclusion is logical in view of the fact that an increase in the addendum diameter led to an increase in flow rate.

The approval that the increase of the teeth number leads to an increase in flow rate is contained in the study [5]. This contradicts the above data. Obviously, it means the overall growth of the transmission dimensions and dimensions of the pump - then this statement is correct but does not make sense. It is confirmed that with the module increase the flow rate increases at the same dimensions. With increasing the gear face width, the flow rate increases - this statement is obvious [5].

The increasing of a pressure angle and a transverse contact ratio is increase the pump flow rate. Also, an increase of the flow rate can be achieved with an increase of the profile shift coefficient [5].

The approval that the flow rate increases with increasing pressure angle is in direct contradiction of the previous publication. Clearly for the final conclusion in this question it is necessary to specify exactly what other parameters change with the change of the pressure angle, and which remain constant. This remark is valid for other cases. The gearing parameters are interrelated, and for involute meshing are standardized, and when studying one parameter, it is necessary to specify which other parameters change. In any case, changes of the pressure angle have little effect on the flow rate.

With an increase of the teeth number, the flow rate decreases, and with the module increase, the flow rate increases [6]. In this study, it is specifically stated that an increase in the teeth number take place at a constant gears diameter. These studies [6] correspond to the data of article [4] in terms of the influence of the teeth number. With an increase of the pressure angle, the flow rate increases, here there is agreement with the research in article [5]. If the addendum coefficient increases, the flow rate is increase, as expected. It is indicated that the addendum coefficient varies slightly from 1.0 to 1.05 . The increase of the gears face width expectedly leads to an increase in theoretical flow rate. The helix angle does not affect flow rate [6]. The data on the relationship between the flow rate and the profile shift coefficient (an increase in the profile shift coefficient leads to a decrease in the flow rate) contradicts the data of the study [5]. Data on the influence of the gears geometrical parameters on the flow rate are summarized in Table 1.

Another way to increase flow rate is to use a different type of profile - cycloidal [5]. A method for accurate calculation of the fluid volume in tooth space with external gearing, both for the involute and non-involute tooth profile has been developed [7]. Using this method, the fluid volume in the tooth space with an involute profile and a cycloidal profile had calculated. Comparison of the flow rate of gear pumps with these two tooth profiles was also performed experimentally. Confirmation by calculation and experimentally of the fluid volume by $20 \%$ increase in the tooth space of a gear pump with a cycloidal tooth profile in comparison with the involute tooth profile was obtained [7].

Table 1. The direction of influence of the gearing parameters on the flow rate $(\uparrow-$ with an increase in the parameter, the flow rate increases, $\downarrow$ - with a decrease in the parameter, the flow rate decreases, $\uparrow \downarrow$ - the effect is multidirectional, 0 - does not affect, the empty cell - hasn't data).

\begin{tabular}{|c|c|c|c|}
\hline & 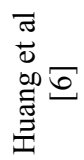 & $\begin{array}{l}n \\
\tilde{\Xi} \\
\bar{d} \\
\frac{0}{\pi} \\
\tilde{n}\end{array}$ & 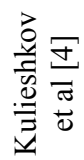 \\
\hline The Number of teeth & $\downarrow$ & $\uparrow$ & $\downarrow$ \\
\hline Module & $\uparrow$ & $\uparrow$ & $\uparrow$ \\
\hline Face width & $\uparrow$ & $\uparrow$ & \\
\hline Profile shift coefficient & $\downarrow$ & & 0 \\
\hline Helix angle & 0 & & \\
\hline Pressure angle & $\uparrow$ & $\uparrow$ & $\downarrow$ \\
\hline Addendum coefficient & $\uparrow \downarrow$ & & $\uparrow$ \\
\hline Addendum diameter & & & $\uparrow$ \\
\hline
\end{tabular}

Comparison of the involute and cycloidal profile showed that the cycloidal profile has lower friction losses. It has been established that cycloidal gearing has greater wear resistance in comparison with involute [8].

Along with many advantages, cycloidal gearing has the disadvantage; this is high contact stress at the pitch point. To overcome this disadvantage there is provided a profile of the tooth flank consists of a portion of an epicycloid addendum, a portion of a hypocycloid dedendum and a small involute portion in the area of the pitch point [9].

Another problem cycloidal meshing - it's sensitivity to changes in the center distance. Increasing the center distance by tenths of a millimeter leads to a large decrease in the transverse contact ratio [10]. This negative phenomenon is observed at different pressure angles and different values of the addendum coefficient.

A comparative analysis of the strength of the involute and cycloidal gearing was carried out [11]. Cycloidal meshing is considered at various pressure angles and different auxiliary (rolling) circle radius. The pressure angle varied from 10 to 28 degrees. The radius of the auxiliary (rolling) circle took values from 5 to $27 \mathrm{~mm}$. With an increase in the radius of the auxiliary circle, the stress in the root of the tooth decrease slightly. The decrease is more noticeable at pressure angles greater than 20 degree. Contact stress decrease sharply with increasing radius of the auxiliary circle, which is associated with an increase in the reduced radius of curvature. Also at contact angles greater than 20 degrees, contact stress decrease most sharply.

Comparison of the contact stress of involute and composite involute-cycloidal gearing showed that the composite involute-cycloid gearing has much greater contact strength. The tooth root stress of involute gearing is greater, however, at optimal values of the pressure angle ( $\alpha=28$ degree) and the radius of the auxiliary (rolling) circle, the difference is less than 10\% [11].

Changing a number of parameters, such as the number of teeth, leads not only to a change in fluid 
volume, but also to a change in other flow characteristics, such as pressure pulsations. The change in the flow value and the pressure pulsations with a change in the geometric parameters have been studied in [12 -15].

The pressure pulsation limits the possibilities for increasing the module, and also imposes restrictions on the change in the geometric parameters of the cycloidal and involute gearing. The number of teeth was recommended $\mathrm{z}=10$ [16]. However, an increase of the radial clearance and the volume of the tooth space while maintaining a constant number of teeth do not lead to a significant increase in pressure pulsation.

It is clear from the above reviewed publications that the parameters that most significantly affect flow rate are: module, the number of teeth and face width. In fact, most researchers increased the dimensions of the transmissions and, accordingly, the gear pump. Flow rate growth with an increase of dimension is an obvious fact, but it is not of interest.

The profile shift coefficient, pressure angle and addendum coefficient influence the pump flow rate slightly. Special parameters affecting the flow rate of gear pumps are: in the involute gearing - the profile shift coefficient $\mathrm{x}$, and in the cycloidal gearing - the ratio of the auxiliary (rolling) circle radius to pitch circle radius $\mathrm{r} / \mathrm{R}$.

It is necessary to link the increase in pump flow rate with the change of the profile shift coefficient and the bending strength of the teeth. For cycloidal gear transmissions, the relationship between flow rate and teeth bending strength not been studied in detail.

The effect of the radial clearance coefficient and root fillet radius on the pump flow rate is not been evaluated or taken into account. Here there are significant reserves to improve flow rate. The limiting is the bending strength of the teeth.

The purpose of the article is:

- to diversify ways of increasing the fluid volume in the tooth space;

- determine the flow rate of gear pumps, depending on the parameters of cycloidal gearing;

- to give a comparative analysis of gear pumps flow rate with involute and cycloidal gearing, taking into account the teeth bending strength.

\section{Increase flow rate of involute gear pump}

A method for estimating the area of the tooth space was developed to assess the effect of the radial clearance coefficient on the pump flow rate with an involute gearing. With the help of the developed program "Gearing", the process of cutting teeth with a rack cutter, a shape cutter and a hobbing cutter is modelled. The tooth profile is obtained using the generation process as an envelope of several cutter positions. The found profile of the tooth space is transmitted to the software program Mechanical Desktop 6.0. The configuration of the tooth space was approximated by a closed broken line and the area was determined using the command "AREA". An example of the obtained configuration of the tooth space is given in Figure 1.

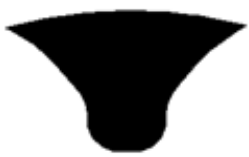

a

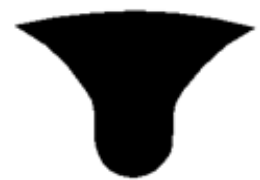

b
Fig. 1. The configuration of tooth space with the number of teeth $\mathrm{z}=12$, profile shift coefficient $\mathrm{x}=0$, root fillet radius coefficient $\rho_{\mathrm{f}}^{*}=0.38$, radial clearance coefficient $\mathrm{c}^{*}=0.25$ (a) and $\mathrm{c}^{*}=0.5(\mathrm{~b})$.

The dependence of the tooth space area for the involute gear for different values of the root radial clearance is found (Figure 2). The tooth space area with a radial clearance coefficient $\mathrm{c}^{*}=0.25$, taken as the baseline, is $100 \%$. The increase in area for large values of the coefficient is given as a percentage of the base.

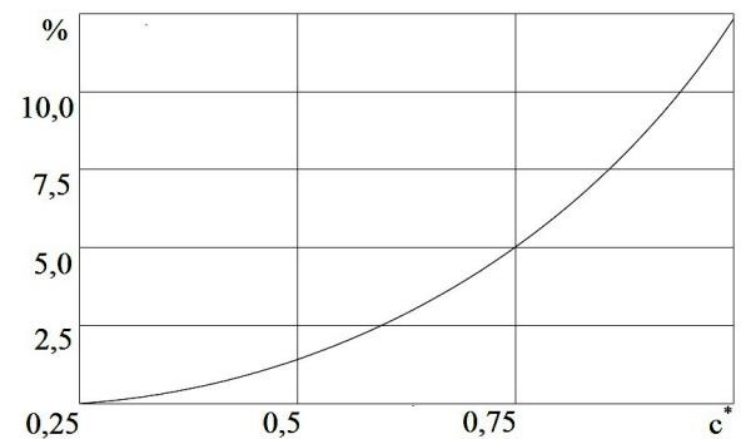

Fig. 2. Dependence of the tooth space area on the radial clearance coefficient $c^{*}$.

As can be seen from the figure, the possibility of increasing the pump flow rate by increasing the radial clearing is significantly greater than by factors such as profile shift coefficient, pressure angle and addendum coefficient. However, an increase in the radial clearance significantly reduces the bending strength of the teeth, which imposes restrictions on the possibility of changing this parameter.

To assess the bending strength of the teeth, the tooth root stress was determined using the finite element method. In the software Mechanical Desktop 6.0, a three-dimensional solid model of the gear sector has been created. Since bending stress arise not only in the root fillets of a tooth that is in meshing, but also in the root fillets of the adjacent teeth, the model includes a tooth under load and adjacent teeth. The model represents a sector of the gear that is bounded by the surface of the shaft sleeve and the radial straight lines that are the axes of the teeth (Figure 3).

It is assumed that a surface of the shaft sleeve is constraint. The load (concentrated force) is applied to the tooth tip along the normal to the involute. It should be noted that ISO 6336 applies force at the upper point of single pair gear tooth contact. With FEM tensions are determined for these two computational cases. The difference in these two cases is less than $2 \%$, in the subsequent calculation the load is applied to the tip of the tooth. 


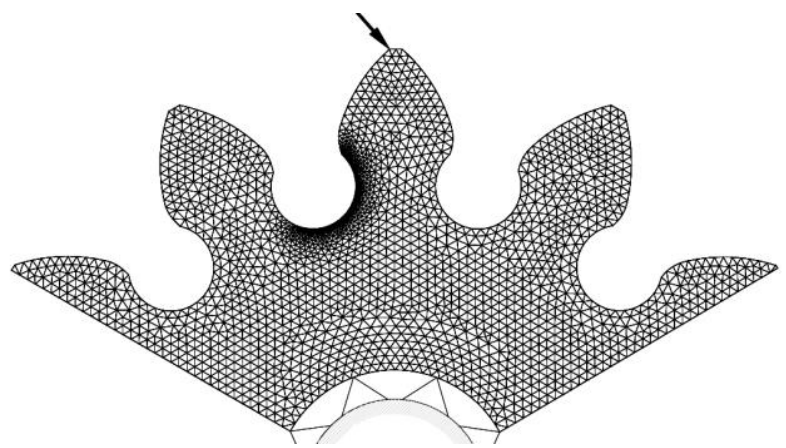

Fig. 3. Solid model of a involute gear sector, divided into triangular finite elements.

The FEM module of Mechanical Desktop automatically carries out the separation of the object into triangular finite element with variable step. After several attempts and result comparisons with those of other authors [17-19] it was established that it is not necessary to use very small elements for a root fillet of the tooth. Sufficient accuracy is provided by elements with a size of about $0.025 \mathrm{~mm}$.

The values of bending stress are calculated for one and the same point as defined by the hypothesis of A.Verhovski. It is assumed that the critical section of the external tooth is determined by the two tangents to the root fillets at $30^{\circ}$ relative to the tooth axis. The stress according to ISO 6336 is defined for the same point, which makes it possible to compare results by different methodologies.

Safety factors have been found on the basis of the calculated stress depending on the radial clearance coefficient (Figure 4).

Comparing the two figures, we see that with increasing area of the tooth space, and, accordingly, the performance of the pump, by $25 \%$, teeth bending strength decreases by about $75 \%$. Thus, although the increase of the radial clearance is more effective compared to the change of other parameters, an increase in the radial clearance should be limited to the range $\mathrm{c}^{*}$ $=0.25 \ldots 0.4$.

\section{Increase flow rate of cycloid gear pump}

The cycloidal profile of a tooth has the addendum contoured by an epicycloid and the dedendum outlined by a hypocycloid. Thus, the addendum has a convex surface, and the dedendum has a concave surface. Due to the concave surface of the dedendum, the area of the $t$ tooth space in the cycloidal gearing is always greater than in the similar involute. The tooth space area of the cycloidal gearing is maximum with the ratio of the auxiliary circle radius to the pitch circle radius is equal 0.5 . In this case, the hypocycloid degenerates into a straight line.

Using the same technique as for involute gearing, the dependence of the tooth space area on the ratio of the circles radii - a dedendum auxiliary and a pitch $\mathrm{r}_{\mathrm{D}} / \mathrm{R}$, was found (Figure 5).

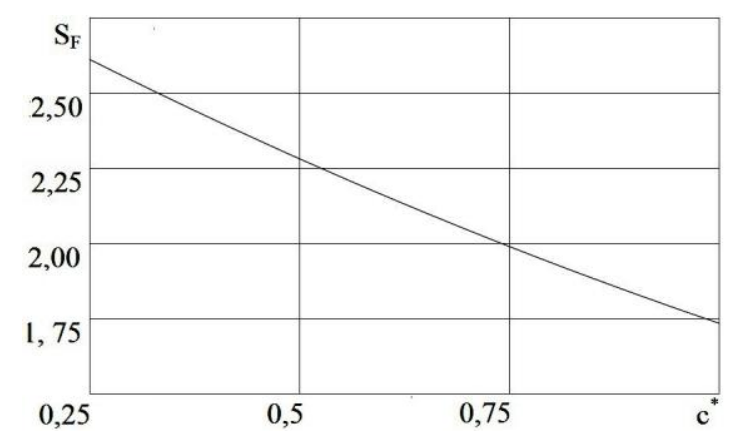

Fig. 4. The dependence of the safety factor on the size of the radial clearance coefficient.

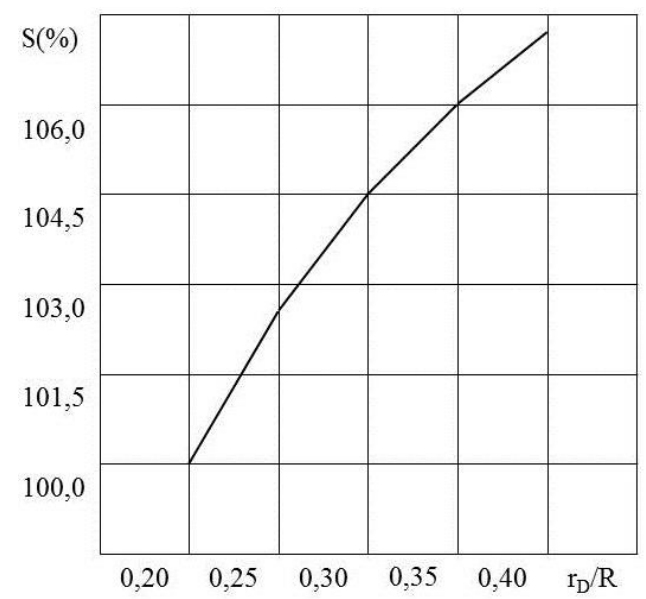

Fig. 5. Dependence of the tooth space area on the ratio circles radii - a dedendum auxiliary and a pitch.

The tooth space area at $r_{D} / R=0.2$ is taken as $100 \%$, the increase in area with an increase in the ratio is indicated as a percentage of the base. The increase in pump performance by increasing the ratio $r_{D} / R$ can be $7.5 \%$.

The influence of the circles radii ratio $r_{A} / R$ - an addendum auxiliary and a pitch was also investigated. The effect of changing the radius of the auxiliary circle on the tooth space area is much less. The increase in pump flow rate due to an increase in the ratio $r_{D} / R$ is less than $2 \%$

Usually, the radii ratio of the addendum auxiliary and pitch circles should be equal to the radii ratio of the dedendum auxiliary and pitch circles of the gear. This imposes certain restrictions, for example, the ratio $r_{D} / R=$ 0.45 is acceptable and provides a large area of the tooth space and, consequently, higher pump flow rate, but with a ratio of $r_{\mathrm{A}} / \mathrm{R}=0.45$, the gear teeth may be wedged. Or if the ratio $r_{A} / R=0.15$ is acceptable and provides a large area of the tooth space, but the ratio $r_{D} / R=0.15$ cannot be recommended.

The dependence of the tooth space area on the radial clearance coefficient is investigated. Considering the decrease in the bending strength of the tooth due to the large value of the $r_{D} / R$ ratio, a narrower range of values radial clearance coefficient $\mathrm{c}^{*}=0.25-0.3$ was investigated. In these narrow variation limits of the radial clearance coefficient, the dependence is almost linear. And close to the values, that were obtained for 
involute gearing. The dependence of the tooth space area on the tooth root fillet radius coefficient $\rho_{\mathrm{f}}^{*}$ was also studied. The difference between the area of the tooth space with the standard value $\rho_{\mathrm{f}}{ }^{*}=0.38$ and the value of $\rho_{\mathrm{f}}^{*}=0.3$ is only $0.3 \%$ with a significant decrease in bending strength. Therefore, the factor of a root fillet radius should not be changed for the purpose of increase the tooth space area.

\section{Comparison involute and cycloid gear pump}

To compare the advantage of using an involute and cycloidal profile in gear pumps, gears with an involute and cycloidal tooth profile having the same parameters were selected. Involute gear parameters: the number of teeth $\mathrm{z}=8$, module $\mathrm{m}=10$, profile shift coefficient $x=$ 0.624 , radial clearance coefficient $c^{*}=0.25$, root radius factor $\rho_{\mathrm{f}}^{*}=0.38$, tooth addendum coefficient $\mathrm{h}_{\mathrm{a}} *=1$. Cycloidal gear parameters: the number of teeth $\mathrm{z}=8$, radial clearance coefficient $\mathrm{c}^{*}=0.25$, root radius factor $\rho_{\mathrm{f}}^{*}=0.38$, the circles radii ratio of an auxiliary and pitch $\mathrm{r} / \mathrm{R}=0.4$ (for the addendum and the dedendum of $\mathrm{a}$ tooth).

In order for the involute gear to be replaced in the pump with cycloidal profile gear, it is necessary that two conditions be performed: the equal center distance of both gears and the equal diameter of the addendum gear circle. We use the system of two equations

$$
\left\{\begin{array}{l}
d_{a}=m z+2 h_{a}^{*} m \\
a_{w}=m \frac{z_{1}+z_{2}}{2}=m z
\end{array}\right.
$$

Solving these equations, we find the cycloidal gear train module $\mathrm{m}=11.25 \mathrm{~mm}$ and the tooth addendum coefficient $h_{a} *=0.9991$.

Involute and epicycloidal profiles are convex and a similar at the selected gearing parameters. The addendum profiles of the teeth practically coincide, but there is no tooth top sharpening in the cycloidal gear. The thickness of the dedendum cycloidal tooth is much less than involute (Figure 6). Therefore, the bending strength of the cycloidal tooth requires additional research. It has been established by calculation that with the above gear parameters, the tooth space area of the cycloidal gear is $27 \%$ larger than the involute one (the tooth space area of the involute gearing is taken as the baseline).

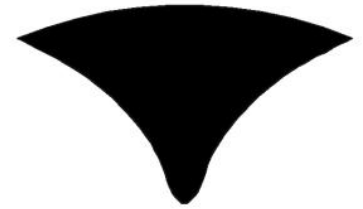

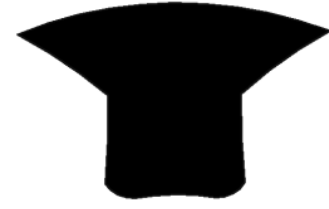

b
Fig. 6. The tooth space configuration of the involute (a) and cycloidal (b) gearing.
The strength of the cycloidal teeth was studied for various $r_{D} / R$ ratios of radii. The safety factor for the considered involute gear is assumed to be 3.0. The safety factors for the cycloid gear are calculated relative to it for various values of the $r_{D} / R$ ratios of radii (Figure 7).

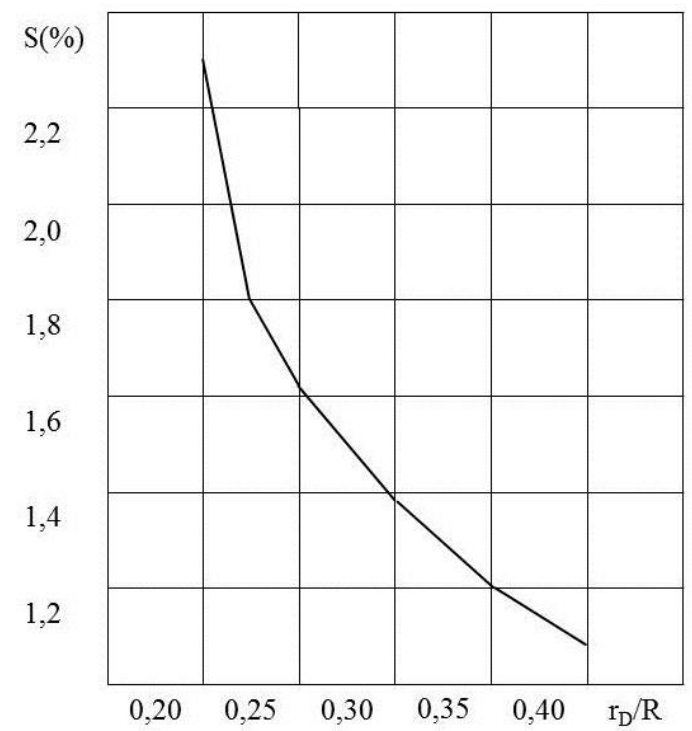

Fig. 7. Dependence safety factor due the different values of the $\mathrm{r}_{\mathrm{D}} / \mathrm{R}$. ratios of radii.

The bending strength of the cycloidal gear, with the number of teeth $\mathrm{z}=17$ and the radius ratio $r_{D} / R=0.2$, is less than the bending strength of the involute gear by only $4.5 \%$. With an increase in the ratio $\mathrm{r}_{\mathrm{D}} / \mathrm{R}$, the bending strength of the cycloidal gearing decreases. When the number of teeth is $\mathrm{z}=17$ and the ratio of the radii $r_{D} / R=0.4$ the bending strength of a cycloidal gear is less than an involute gear by $28.5 \%$. Considering that the gear strength is determined, first of all, by the maximum contact stress, such a reduction of the bending strength is often acceptable. With a decrease in the number of teeth, the bending strength of the cycloid gearing depends more strongly on the auxiliary and pitch circles radii ratio. The use of the radii ratio $r_{D} / R=0.4$ when the number of teeth $\mathrm{z}=8$ cannot be recommended.

There are a large number of parameters affecting the area of the tooth space and. accordingly, the pump flow rate. Changes in these parameters have the greatest effect on the bending strength of a tooth. However, any change in the gearing geometric parameters leads to a change in contact strength, wear resistance, and requires a change in the parameters of the gear cutting process.

To estimate the whole complex of parameters is extremely difficult. A comparative assessment of two pumps types using the fundamental design method (FDM) was performed [20, 21]. The following factors were chosen: the area of the tooth space (a), manufacturability (b), contact strength (c), wear resistance (d), and bending strength (e). At the triangle tables put down the numerical values. These values were assigned to each of the combinations of the elements (Figure 8). 


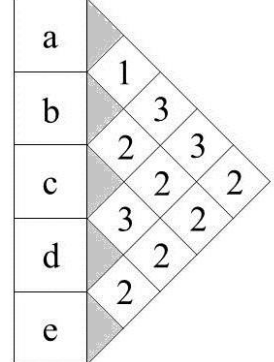

a

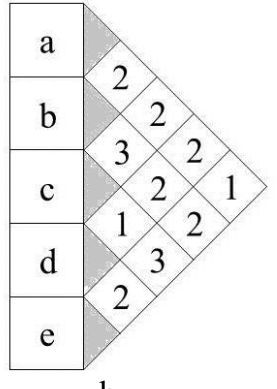

b
Fig. 8. Evaluation of gear pumps with cycloidal (a) and involute (b) gearing using FDM method.

For example, we consider that it is more difficult to vary the tooth space area in the cycloidal gearing than in the involute ones. Therefore, the combination of a manufacturability - an area in the first case, is the "1", and in the second "2". In a combination of factors, contact strength - wear resistance, the advantage of cycloidal gearing is obvious - a score of "3", and for involute gearing " 1 ".

The total of the estimates is the degree, to which the design corresponds to the task. As a result of application of the method it was found that the cycloidal gear pumps is better; its score is 22 , whereas the involute gear pumps has the score of 20.

\section{Conclusion}

The main gearing parameters affecting pump performance are the module and the number of teeth. These parameters are interrelated. Increased performance with the same dimensions of pump can be achieved by increasing the module and at the same time reducing the number of teeth. Reducing the number of teeth leads to flow pulsation. Therefore, this way to improve pump performance has its limitations.

The next most influencing factor on pump flow rate is the radial clearance coefficient. This factor is not given due attention. By increasing the radial clearance coefficient, it is possible to increase by $5 \%$ the flow rate of a pump with involute gearing and by $7 \%$ of a pump with cycloidal gearing.

The next factor in terms of impact on pump flow rate is the profile shift coefficient for involute gears and the radii ratio of the auxiliary and pitch circles for cycloidal gears. By changing the profile shift coefficient, you can increase the pump flow rate by $2-4 \%$, and by changing the radii ratio by $3-5 \%$.

The simultaneous use of involute gears with an undercut of the tooth and an increased value of the radial clearance coefficient allows an increase in flow rate of 8$11 \%$. This is more than the addition of flow rate gains from the impact of each of these factors separately.

The simultaneous use of increased values of the auxiliary and pitch circles radii ratio, as well as increased values of the radial clearance coefficient, allows you to get an increase in flow rate by $14-17 \%$. This is more than the addition of flow rate gains from the impact of each of these factors separately.
The use of undercut teeth with a simultaneous increase in the radial clearance coefficient leads to a large decrease of their bending strength. Also the simultaneous use of increased values of the auxiliary and pitch circles radii ratio, as well as increased values of the radial clearance coefficient leads to a decrease of teeth bending strength. When designing a pump with such gearing parameters, it is necessary to calculate bending stress using methods which allow accurately reflect the actual shape of the tooth - the finite element method, boundary element method, and others.

In pump gears, the contact strength limits the size of the transmission. There is always some margin of bending strength. Reducing the bending strength can increase pump flow rate. In cycloidal gearing, with the same increase in bending stress as in involute gearing, it is possible to obtain a greater gain in pump flow rate.

The area of cycloidal gearing functioning in gear pumps is determined. On the basis of design experience, we can recommend the following limits of geometric parameters variation: the number of teeth $\mathrm{z}=8 \ldots 15$, auxiliary and pitch circles radii ratio $\mathrm{r} / \mathrm{R}=0.2 \ldots 0.3$, module $\mathrm{m}=4 \ldots 10 \mathrm{~mm}$, root fillet radius coefficient $\rho_{\mathrm{f}}{ }^{*}$ $=0.38$, radial clearance coefficient $\mathrm{c}^{*}=0.25 \ldots 0.35$.

\section{References}

1. K. Mori, T. Maeno, Y. Fukui CIRP annals, 60(1), 299-302 (2011)

2. K. Gupta, N. Jain The International Journal of Advanced Manufacturing Technology, 72(9-12), 1735-1745 (2014)

3. C. Özel The International Journal of Advanced Manufacturing Technology, 54(1-4), 203-213 (2011)

4. Iu. Kulieshkov, M. Chernovol, T. Rudenko, V. Hutsul, R. Osyn Zbirnyk naukovykh prats KNTU: Tekhnika v s/h vyrobnytstvi, haluzeve mashynobuduvannia, avtomatyzatsiia, 23, 378-390 (2010)

5. M. Saleem TJES, 16(4), 20-27 (2009)

6. K. Huang, C. Chen, Y. Chang Proc. of the Inst-on of Mech. Eng., Part C: JMES, 223(9), 2191-2199 (2009)

7. K. Nagamura, K. Ikejo T. Toyoshima Proc. of the Inst-on of Mech. Eng. Part B. Journal of engineering manufacture, 218 (7), 699-711 (2004)

8. K. Ikejo, K. Nagamura, F. Tutulan In ASME Intern. Des. Eng. Technical Conf. and Comp. and Inform. in Eng. Conf., 657-663 (2005)

9. F. Tutulan, K. Nagamura, K. Ikejo, In ASME Intern. Des. Eng. Technical Conf. and Comp. and Inform. in Eng. Conf., 91-96 (2003)

10. N. Seyama, K. Nagamura, K. Ikejo Transactions of the JSME Series C, 77, (775) 582-590 (2011)

11. F. Tutulan, K. Nagamura, K. Ikejo In: The Proc. of the Symp. on Motion and Power Transmission JSME, 35-38 (2004) 
12. E. Frosina, A. Senatore, M. Rigosi Energies, 10(8), 1113. (2017)

13. W. Wang, Y. Yin, S. He, G. Liu J of Applied Science and Eng., 20(3), 367-372 (2017)

14. N. Manring, S. Kasaragadda J. of dynamic systems, measurement, and control, 125(3), 396-404 (2003)

15. H. Kim, Two-dimensional CFD analysis of a hydraulic gear pump (2007)

16. Q. Sun, Y. Sun, L. Li Advances in Mechanical Engineering 10(1) (2018)

17. W. Yu-Ren and Y. Guang-Yi IJCIRA, 6(1), 1-8 (2012)

18. A. Kawalec, J. Wiktor, D. Ceglarek J of Mech, Des., 128(5), 1141-1158 (2006)

19. K. Lokesh, K.Vivek D. Mahesh IRJET 4 (7) (2017)

20. V. Ivanov, G. Urum, S. Ivanova, M. Volkova, East.Eur. J. of Enterprise Technolog., 1, 3, 43-50 (2018)

21. V. Ivanov, G. Urum, S. Ivanova, G. Naleva East.Eur. J. of Enterprise Technolog., 4, 1, 11-17 (2017) 